\title{
Metastatic Esophageal Carcinoma
}

National Cancer Institute

\section{Source}

National Cancer Institute. Metastatic Esophageal Carcinoma. NCI Thesaurus. Code C156073.

A carcinoma that arises from the esophagus and has metastasized to another anatomic site. 